\title{
RELAÇÃO ENTRE RECURSOS NATURAIS, IDENTIDADES TRADICIONAIS E LÍNGUAS NA AMAZÔNIA BRASILEIRA ${ }^{l}$
}

\author{
RELATION BETWEEN NATURAL RESOURCES, TRADITIONAL IDENTITIES AND \\ LANGUAGES IN THE BRAZILIAN AMAZON
}

Resumo: O objetivo deste artigo é apresentar e discutir algumas das razões que têm causado a perda progressiva de parcela significativa de recursos naturais no Brasil, em especial, na Amazônia Brasileira e, as consequências dessa perda para a manutenção do modo de vida das populações tradicionais em relação aos seus territórios, suas identidades e suas línguas, com destaque para os povos indígenas que são um dos maiores responsáveis pela conservação da natureza. Os dados são provenientes de sites, artigos científicos e no caso dos dados linguísticos, do trabalho de campo do autor. Concluiu-se que o progresso prometido com a exploração dos recursos naturais da Amazônia, não resultou satisfatório para a grande maioria da população brasileira, em especial as populações tradicionais.

Palavras-chave: Línguas indígenas. Recursos naturais. Populações tradicionais.

\section{Edson Freitas GOMES (UNIFESSPA) $)^{2}$}

\begin{abstract}
This aim of this article is to present and discuss some of the reasons that have caused the progressive loss of a significant portion of natural in Brazil, especially in the Brazilian Amazon, and the consequences of this loss for the maintenance of the traditional people's way of life in relation to their territories, their identities and their languages, with emphasis on indigenous people who are one of the most responsible for nature conservation. The data comes from websites scientific articles and in the case of the linguistic data, from the author's fieldwork. It was concluded that the progress promised with the exploitation of the natural resources of the Amazon, was not satisfactory for the great majority of the Brazilian population, especially the traditional populations.
\end{abstract}

Keywords: Indigenous languages. Natural resources. Traditional populations.

\footnotetext{
${ }^{1} \mathrm{O}$ presente artigo foi apresentado na mesa-redonda 'Povos Indígenas: Interfaces entre cultura (s), territorialidade(s) e meio ambiente), no II Encontro Acadêmico dos cursos de Biologia, Engenharia Florestal e Letras, no Instituto de Estudos do Xingu da Universidade Federal do Sul e Sudeste do Pará, em 19 de junho de 2020.

${ }^{2}$ Mestre em Letras: Lingüística e Teoria Literária pela Universidade Federal do Pará (2013). Atualmente é coordenador do Laboratório de Ensino (LabEns) do Instituto de Estudos do Xingu, Universidade Federal do Sul e Sudeste do Pará (Unifesspa).Email: edsongomes@unifesspa.edu.br
} 


\section{INTRODUÇÃO}

Este artigo tem o objetivo de discutir como ocorre o processo histórico de destruição dos recursos naturais e as consequências disso para a alteração do modo de vida, incluindo cultura e língua, das populações tradicionais da Amazônia Brasileira.

Com o discurso de povoar a Amazônia para não entregar a grupos estrangeiros, o Governo Brasileiro desde a década de 1970 intensificou o processo de ocupação da região, com o incentivo a imigração de populações vindas de várias regiões do Brasil, em especial do Nordeste. Com a vinda desses imigrantes o Governo Brasileiro pretendia resolver dois problemas, o primeiro seria a distribuição de terras para pessoas sem terras e o segundo seria a povoação de áreas 'vazias' e vulneráveis à invasão estrangeira.

No entanto, após anos seguidos de execução dessa prática, o resultado foi a geração de graves problemas que vão desde impactos ambientais até conflitos sociais, com o aumento da violência contra as populações tradicionais que perderam seus espaços de produção, sobrevivência e de identidade, e em muitos casos migraram para áreas urbanas, gerando sérios conflitos sociais, como falta de moradia, subemprego, entre outras mazelas.

O artigo está estruturado em 6 seções. Começando pela introdução. A seção dois trata dos modelos de desenvolvimentos e os impactos ambientais causados. A seção três aborda sobre a alteração que os modelos de desenvolvimento causaram para as populações tradicionais. A seção quatro fala sobre a perda das línguas dos povos originários. A seção cinco trata especificamente do povo Mẽbêngôkre e finalmente a conclusão que faz um apanhado dos temas abordados.

\section{OS MODELOS DE DESENVOLVIMENTO E OS IMPACTOS AMBIENTAIS CAUSADOS}

Os modelos de desenvolvimento econômico propostos para a Amazônia e executados por meio dos grandes projetos, estão associados a ação predatória ao meio ambiente e às populações tradicionais que ocupam esse espaço há séculos.

Dentre os projetos de desenvolvimento econômico executados na Amazônia Brasileira, podese destacar alguns, tal como os ciclos da borracha, que ocorreram de 1879 a 1912 e durante a Segunda Guerra Mundial; a implantação da rodovia Transamazônica, inaugurada na década de 1970; a construção de hidrelétricas como a de Belo Monte no rio Xingu; a mineração Grande Carajás; a pecuária extensiva; a extração de madeira; a mineração, entre outros. 
Como resultado dessas políticas desastrosas, pode-se elencar o impacto causado por meio do desmatamento de grandes áreas de floresta nativa para, em um primeiro momento, a extração de madeira e a instalação da pecuária extensiva, e, mais recentemente para a plantação de culturas como o milho e a soja, que visam abastecer de grãos o mercado nacional e principalmente, o internacional, em detrimento de uma produção baseada em agricultura familiar.

De acordo com portal de notícias terra "Na safra de 2018/2019, 64\% das novas áreas plantadas estavam no bioma amazônico”. Já de acordo com o site Rede Amazônica de Informação Socioambiental Georreferenciada “Amazônia tem mais 2,5 mil garimpos ilegais e contaminação por mercúrio vira regra". As figuras 1 e 2 a seguir mostram a produção de grão no país e o garimpo ilegal, com o aumento do desmatamento ilegal e a contaminação de rios, respectivamente.

Figura 1: Plantação de soja na Amazônia

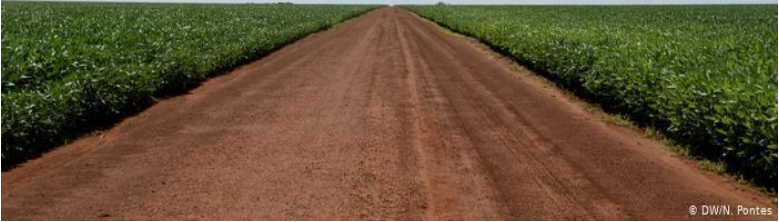

Fonte: DW Brasil, Pontes $(2020)^{3}$
Figura 2: Garimpo ilegal na Amazônia

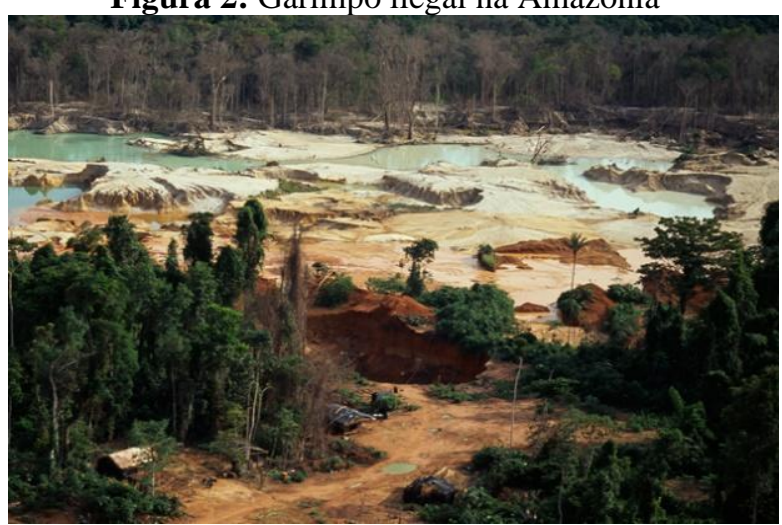

Fonte: Hypeness, Paiva (2018/2019)

A poluição dos rios amazônicos, provocada pela mineração ilegal é outra prática devastadora, que coloca em xeque a sobrevivência dos povos que dependem dos rios para atividade de pesca e para suas necessidades diárias, pois, o mercúrio utilização na mineração e despejado nos rios contamina os peixes, que ficam inapropriados para consumo. Essa prática atinge os estados amazônicos e os povos indígenas são os mais afetados, conforme relato feito por órgãos como o Instituto Socioambiental que destaca "Pedido de retirada de garimpeiros da Terra Indígena Yanomami chega na OEA”.

O chamado arco do desmatamento, ou arco do fogo, vem avançando ao longo dos anos, na divisa dos estados do Maranhão, Pará e Mato Grosso e segue em direção ao extremo oeste da Amazônia Brasileira, Sul do Amazonas Rondônia e Acre, com grande poder de destruição dos

\footnotetext{
${ }^{3}$ Disponível em: https://www.dw.com/pt-br/o-avan\%C3\%A7o-ilegal-da-soja-sobre-a-floresta/a-52242760

${ }^{4}$ Disponível em: https://www.hypeness.com.br/2018/12/amazonia-tem-mais-de-25-mil-garimpos-ilegais-econtaminacao-por-mercurio-vira-regra/
} 
recursos naturais, incluindo espécies de flora e fauna. $\mathrm{O}$ avanço dessas práticas tende a diminuir cada vez mais os recursos naturais disponíveis, o que pode colocar em xeque a capacidade de sobrevivência de populações que sobrevivem exclusivamente destes recursos, como os índios isolados.

\section{ALTERAÇÃO NO MODO DE VIDA DAS POPULAÇÕES TRADICIONAIS}

A alteração do modo de vida das populações tradicionais é uma das mais graves consequências da implantação dos projetos inadequados para a realidade amazônica, pois, com o avanço dos projetos de desenvolvimento, às populações tradicionais ficaram cada vez mais expostas a graves problemas como a falta de terra para cultivar, rios para pescar, violência, epidemias e uma tensão constante para manter seus territórios tradicionais.

A invasão das terras indígenas na Amazônia por madeireiros, garimpeiros, e outros atores de exploração tem gerado muitos conflitos, muitas vezes com a perda de vidas, como é o caso dos indígenas Guajajara no estado do Maranhão que nos últimos anos já viram alguns dos seus guardiões serem mortos por invasores. Nesta reportagem da revista Exame de 2019 'Polícia confirma morte do $4^{\circ}$ indígena no MA em menos de um mês' pode-se ter a dimensão da gravidade do problema para este e outros povos que vivem na floresta.

Os indígenas passaram da condição de donos das terras no passado, em que viviam em casas construídas em harmonia com a natureza, conforme figura 3 a seguir, para a realidade em que muitos indígenas vivem hoje na condição de sem-terra no seu próprio território ancestral. Este é o caso de alguns Guarani-Kaiowá no Mato Grosso do Sul, às margens de rodovias, que vivem às margens de rodovias, conforme figura 4 a seguir.

Figura 3: Mulheres na Roça

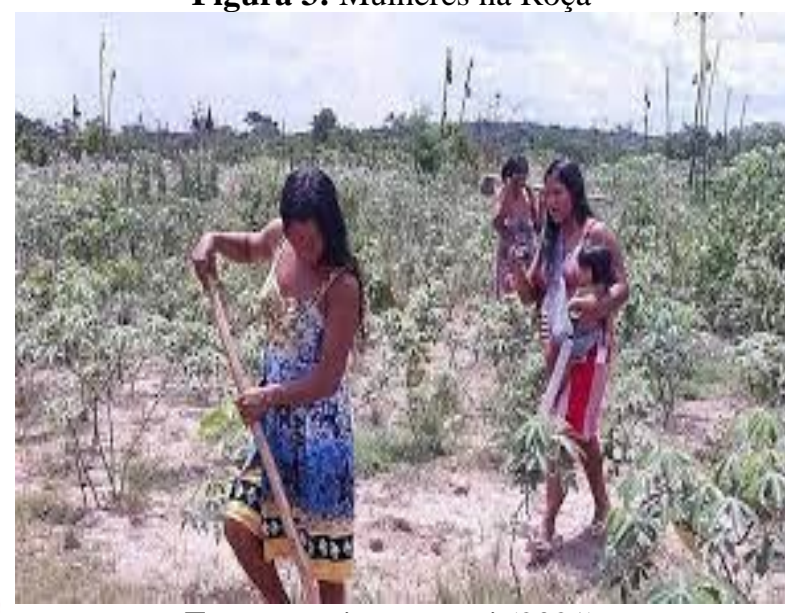

Fonte: Instituto Raoni (2021)

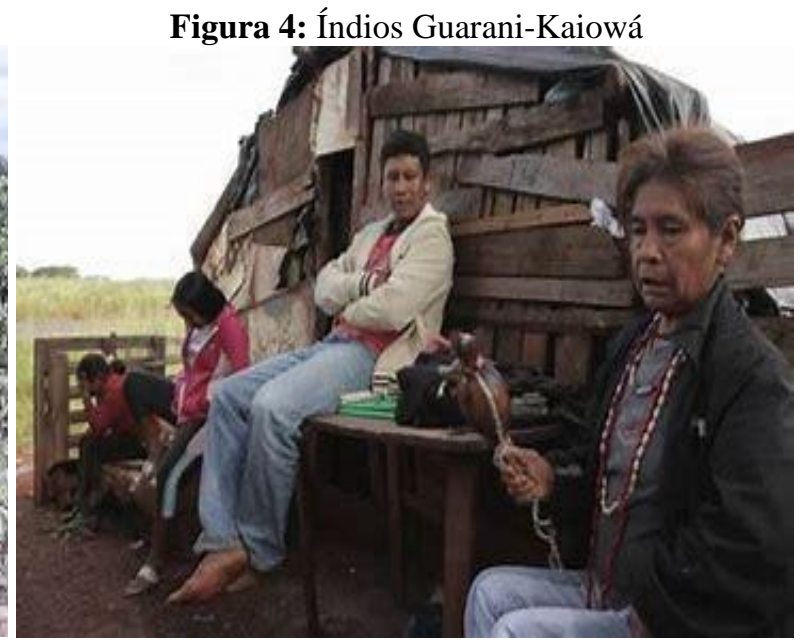

Fonte: Careli (2016) 
A história dos indígenas com as epidemias é uma constante desde o início do contato com o colonizador. Estudos indicam que ao longo dos mais de 500 anos de colonização do Brasil, os indígenas sempre estiveram expostos às mais variadas epidemias, tais como varíola, sarampo, gripe, entre outras.

Segundo Turner (1991), desde 1940 os Irã'ãmrayre, grupo de Mẽbêngôkre/Kayapó de Pau D’arco no Pará, são considerados extintos, vitimados por uma epidemia. Dos aproximadamente mil indígenas existentes em 1909, 30 anos depois já não existiam mais. Com a atual epidemia de covid19, já há 3.308 casos e 33 óbitos, somente na bacia do rio Xingu, segundo dados da Rede Xingu+, publicados em 06 de novembro de 2020.

O modo de viver e de pensar do indígena é muito diferente da cultura ocidental. A relação do indígena com a natureza não é uma relação de sujeito para objeto, e sim, de sujeito para sujeito. Para muitos indígenas ele é a própria natureza e vice-versa. Nas palavras de Todorov (2011) "as culturas ameríndias oferecem um modo de ser e pensar próprio, radicalmente 'outro' com relação ao Ocidente". Na figura 5 a seguir, observa-se um ritual do Xingu, em que há uma relação harmoniosa entre os indígenas e a natureza.

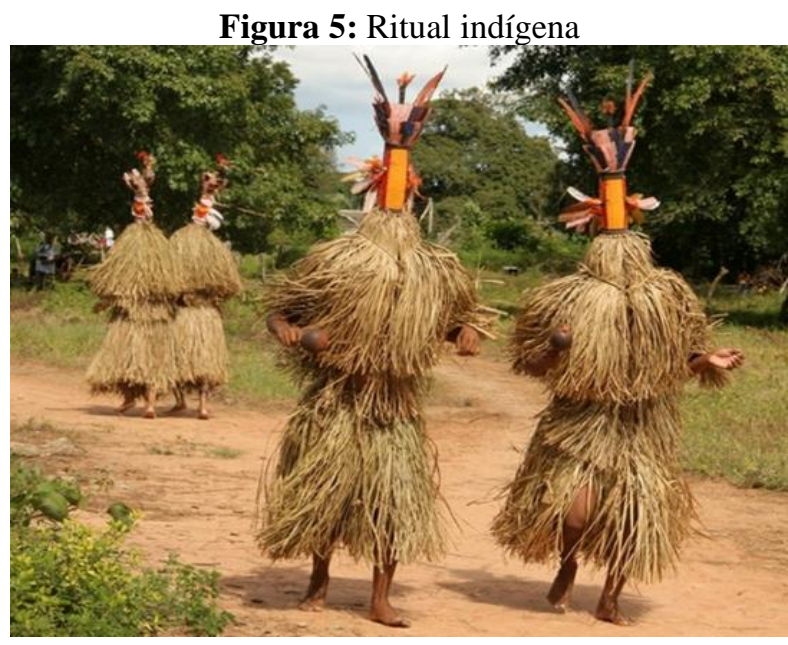

Fonte: Araújo (2018)

Na figura 6 a seguir, há o esboço de algumas das diferenças que existem entre o modo de vida indígena para o modo de vida do Ocidente.

Tabela 1: Diferença entre a cultura ameríndia e a ocidental

CULTURAS AMERÍNDIAS

Relação entre mim e o outro (humano ou não humano) 


$$
\text { Relação sujeito } \leftrightarrow \text { sujeito }
$$

(simetria, reciprocidade, troca, reversibilidade).

Ao abarcar sujeitos humanos e não humanos, estabelece o domínio universal da Cultura.

Cosmocentrismo e pluralismo cosmológico

(admite uma pluralidade de sujeitos não humanos:

plantas, animais, artefatos, espíritos etc.).

'Produção' de sujeitos e subjetividades de sociabilidades.

Relação com o invisível (interior, intensivo, subjetivo) que também é o anímico, o espiritual.

$$
\text { O outro é um 'eu' }
$$

(um sujeito, um rosto, um olhar, uma fala, um pensamento, um modo de ser, um ponto de vista).

Ser olhado/afetado pelo outro.

Relação social, dialógica, ética e poética.

Alteridade (o novo, o diferente).

Pensamento poético/metafórico.

A é B (torna-se outro).

'Eu é um outro'.

O homem pertence à terra.

A terra é 'mãe' (sujeito feminino).

Cultura da floresta -

mata cultural, floresta-pomar, floresta-jardim

(a floresta que é jardim, sem deixar de ser floresta).

Aumento da biodiversidade

Amazônia antropogênica

Natureza $\leftrightarrow$ Cultura

A floresta como 'sujeito'.
Relação sujeito $\rightarrow$ objeto

(assimetria, representação, poder, dominação, posse).

Cria a Natureza-objeto, em oposição ao

Homem-sujeito, detentor de Cultura.

Antropocentrismo

(egocentrismo, etnocentrismo,

eurocentrismo, falocentrismo etc.).

Produção de objetos, mercadorias.

$\mathrm{O}$ triunfo das coisas.

Relação com o visível (exterior, extensivo, objetivo).

Negação do outro

(escravismo, racismo, xenofobia, homofobia, tortura, feminicídio, etnocídio, genocídio).

Olhar (ou deixar de olhar) o outro.

Negação da ética.

Identidade (o mesmo).

Pensamento lógico.

A é A, B é B.

A terra pertence ao homem.

Negação da floresta -

sua conversão em madeira, celulose, carvão, pasto, monocultura, mineração, rodovia, ferrovia, cidade.

Perda de biodiversidade

Amazônia antropizada

$$
\text { Natureza } \rightarrow \text { Cultura }
$$

A floresta como natureza, meio ambiente ou paisagem ('objeto' do nosso olhar estético-cultural, das nossas representações artísticas, do nosso conhecimento científico, das nossas leis de proteção).

Fonte: Adaptado de Pardini (2020)

As populações tradicionais que embora sejam taxadas em alguns momentos como empecilho ao desenvolvimento do país, na verdade são detentoras de conhecimentos muito avançados. Na época da colonização do Brasil pelos europeus, havia populações tradicionais que já tinham conhecimento 
sobre espécies da flora que superam muito o conhecimento dos europeus. Com poucas horas de trabalho diário, algumas populações conseguiam não apenas o sustento, mas o estoque de alimentos. Segundo Caldeira (2017):

No século XVI, os médicos europeus manipulavam algo em torno de uma centena e meia de espécies vegetais, algumas populações tradicionais, trabalhavam com cerca de 3 mil espécies. [...] Numa época em que a fome era um flagelo na Europa, os Tupi-Guarani se constituíam em exceção de relativa fartura.

Mas apesar da abundância na produção, Caldeira (2017), observa que os Tupi adotavam soluções para manter a igualdade social, fazendo da produção uma prática ligada à preservação.

A maior parte da área preservada no Brasil está localizada nas terras indígenas e nas áreas de proteção ambiental. Segundo dados do Instituto Socioambiental, as terras indígenas ocupam 13\% do território nacional e funcionam como um freio ao avanço do desmatamento e à manutenção da fauna e da flora.

Figura 6: Terras indígenas do Brasil

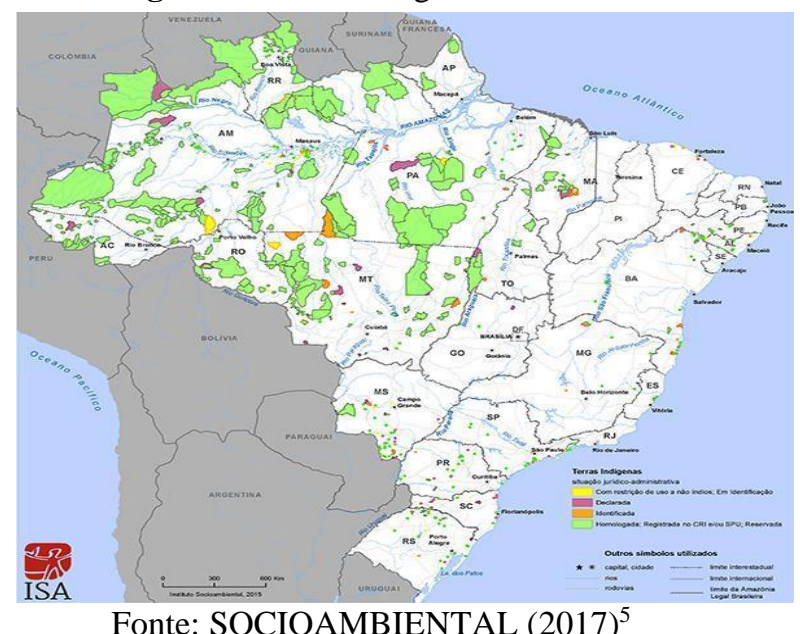

Na figura 6, observa-se que as áreas coloridas no mapa do Brasil, são de terras indígenas, em diferentes processos de demarcação. Essas áreas, juntamente com as áreas de preservação, correspondem à grande parte da área total do Brasil, preservada, e, se concentra predominantemente na Amazônia.

${ }^{5}$ Disponível em: https://www.socioambiental.org/pt-br/mapas/terras-indigenas-do-brasil-janeiro-2017 


\section{PERDA DAS LÍNGUAS ORIGINÁRIAS}

Conforme fora falado na seção anterior, com a perda de suas terras as populações tradicionais tendem a perder seus modos de vida tradicionais, o que envolve cultura, costumes, entretenimento, entre outros. Nesse pacote de perdas, a língua nativa é um dos mais relevantes, pois, além de servir como meio de comunicação da população, carrega um repertório de conhecimento de toda a história do povo, tais como valores culturais, por exemplo, que podem ser perdidos com a morte da língua.

Se pensamos na árvore genealógica de Schleicher, comparatista do século XIX, as línguas assim, como as plantas e os animais, têm um ciclo de vida que se inicia com o nascimento, passa pelo crescimento e se encerra com a morte, mas que pode ter esse ciclo interrompido por ação de agentes ou de fenômenos da natureza.

No caso das línguas indígenas, a ameaça de extinção é constante, pois, além da perda de território pelo povo, essas línguas são faladas por populações estigmatizadas, o que as tornam vulneráveis frente às línguas de povos dominantes, como a língua inglesa, a título de exemplo, e como o preconceito é contra o falante e não contra a língua (cf. BAGNO, 2000), a tendência é que os próprios falantes deixem de usá-las se não houver uma política de conscientização e valorização.

A esse respeito Janson (2015) afirma que há dez mil anos atrás existiam em torno de doze mil línguas no mundo, hoje só resta próximo da metade, em torno de seis mil e novecentos. Próximo de 95\% da população mundial fala apenas trezentas línguas, o restante fala somente 5\%. Ou seja, muita gente falando poucas línguas e poucas pessoas falando muitas línguas.

De acordo com Couto (2009, p. 13):

Frequentemente línguas minoritárias são devoradas por línguas mais poderosas, como o português devorou cerca de mil línguas ameríndias aqui no Brasil em apenas 500 anos. Entre as que sobreviveram, a maioria está em avançado processo de obsolescência, o que significa que, se não houver uma força externa que freie o processo, dentro de alguns anos estarão extintas.

Mostrando essa realidade em dados, tem-se que em 1500 havia cerca de 1.175 línguas indígenas no Brasil, hoje há cerca de 150 a 180 e um total de 230.000 falantes (cf. RODRIGUES, 1993). A tendência é que este número caia com o passar do tempo, pois, muitas línguas estão em perigo de extinção devido ao baixo número de falantes e ao fato de algumas crianças não estarem aprendendo mais a língua nativa (cf. MOORE, 2011).

Em comunicação apresentada em 2020, Galúcio mostrou exemplos de línguas amazônicas do Estado de Rondônia que se encontram em avançado estado de ameaça. O Sakurabiat com 12 falantes, 
Wayoro com menos de 10 falantes e o Puruborá com apenas 2 falantes são algumas das muitas línguas indígenas brasileiras que, depois de anos de ataques sofridos pelo processo de colonização, parecem viver seus últimos momentos.

\section{OS MẼBÊNGÔKRE}

Hoje, as terras ocupadas pelas populações tradicionais podem ser consideradas 'ilhas', pois, são pequenas áreas envolvidas por diferentes tipos de atividades econômicas, o que reforça a tensão constante sobre estas 'ilhas'. Na figura 6, observa-se que essas chamadas ilhas variam de tamanho conforme a região do Brasil. Para a parte mais ao Leste, as áreas indígenas são em regra minúsculas, ao passo que para a parte mais a Oeste, as áreas são bem maiores. Isso se deve ao fato de se aproximar da Amazônia que é considerada a última fronteira do processo de colonização do território brasileiro.

Se o território pode ser considerado uma ilha, as línguas das populações também podem ser consideradas ilhas linguísticas. Conforme observou Couto (2009, p. 165): ilha linguística "é uma pequena comunidade linguística inserta no território de outra comunidade linguística. Uma ilha linguística só se mantém, quando se mantém, devido a uma forte consciência da própria identidade frente à da sociedade envolvente".

Ainda na figura 6, observa-se que na divisa do Mato Grosso com o Pará localiza-se uma área contínua. No Mato Grosso encontra-se o parque do Xingu, criado na década de 1960, que abriga vários povos de diferentes grupos linguísticos. Já na parte do Pará encontra-se o território Mẽbêngôkre, uma ilha de floresta cercada de pastagens, constituída por um conjunto de cinco Terras Indígenas contíguas (Baú, Kayapó, Mekragnoti, Badjônkôre, Capoto/Jarina) (cf. LÓPEZ GARCÉS, LAQUES e COELHO-FERREIRA, 2012).

De acordo com SIASI/SESAI (2014), são 11.675 Kayapó e, de acordo com FUNASA (2011), são 1.818 Xikrin, totalizando 13.493 Mẽbêngôkre, segundo dados disponíveis em ISA (2019). Os Mẽbêngôkre habitam em aldeias que variam de tamanho, algumas como a aldeia Moxkàràkô, com aproximadamente 440 pessoas e outras como a aldeia Apexti, com aproximadamente 87 pessoas, de acordo com dados fornecidos pela CASAI/SESAI de São Félix do Xingu, no ano de 2018. A foto a seguir é da aldeia Moxkàràkô, localizada no rio Zinho, tributário do rio Fresco, que por sua vez é tributário do rio Xingu, no município de São Félix do Xingu. 
Figura 7: Aldeia Moxkàràkô.

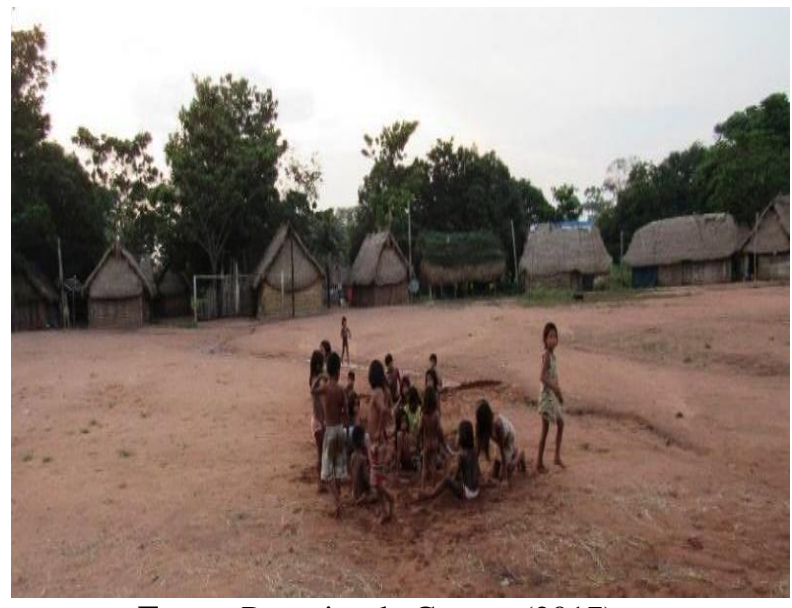

Fonte: Pesquisa de Campo (2017)

Os Mẽbêngôkre realizam diversas atividades direcionadas para a subsistência, tais como o plantio e cultivo de roças, pesca e caça; econômicas, em que se destaca a coleta de castanha, quando passam um período do ano nos castanhais para vender o produto no mercado local e, culturais, como dança e produção de artesanato, este último também é vendido uma parte para uma associação parceira, e pintura corporal. A seguir observa-se duas fotos que retratam o momento de atividades deste povo.

Figura 8: Confecção de pulseira

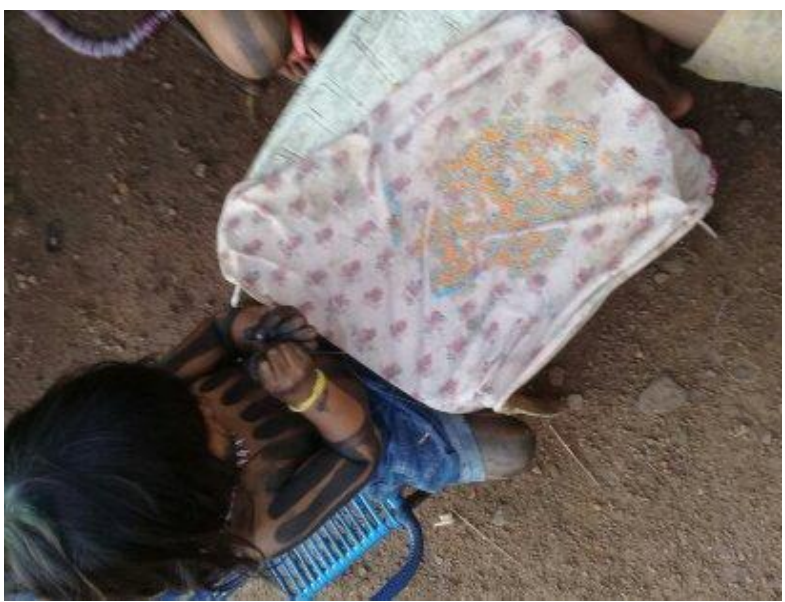

Fonte: Pesquisa de Campo (2018)
Figura 9: Pintura Corporal

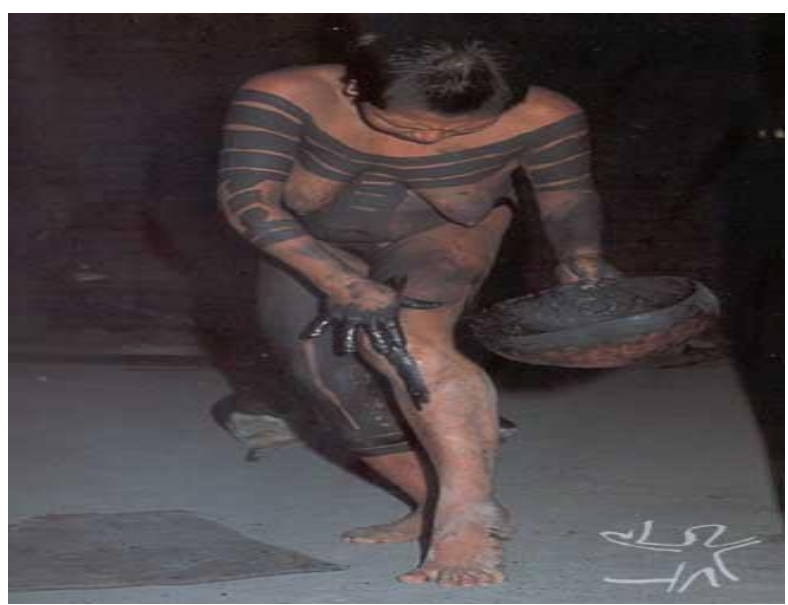

Fonte: Verswijver, (1991)

Neste trecho de Tiago Araújo da Agência Museu Goeldi 'Quando se fala em extinção, relacionamos imediatamente esse termo com espécies de fauna e flora. Entretanto, pouco se sabe sobre outras 'espécies’ que também estão seriamente ameaçadas: as línguas indígenas', pode-se ter a dimensão do que significa perder uma língua, pois, quando se perde uma espécie animal ou vegetal, se perde uma parte significativa e fascinante da natureza. 
Da mesma forma, quando se perde uma língua, se perde uma riqueza de informações relacionada a realidade cultural do povo que a fala, que perde parte da sua história e identidade. Além disso, se perde riqueza de informações gramaticais que se não forem registradas, deixam de existir, conforme os exemplos a seguir.

Tabela 2: Dados gramaticais do Mẽbêngôkre.

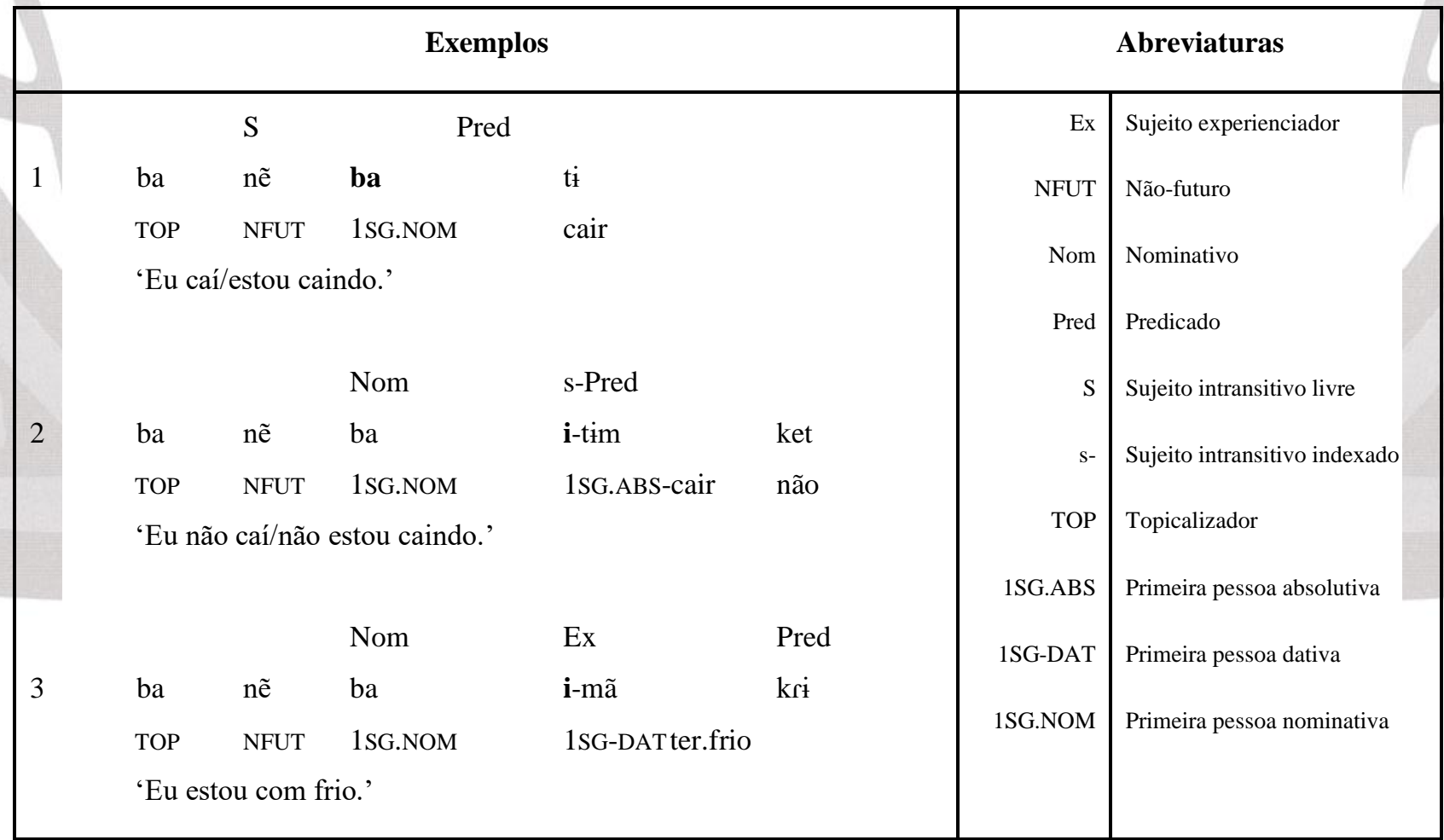

Fonte: Análise de dados (2021)

Nos exemplos acima, observa-se que os predicados apresentam três formas diferentes de representar o argumento sujeito. No exemplo (1), o sujeito ba é independente, nominativo, ao passo que, no exemplo (2), o sujeito i 'eu' é indexado no verbo, absolutivo. Estes dois sujeitos são marcados canonicamente. Já no exemplo (3), o sujeito i 'eu' é marcado de forma diferente dos outros dois, ele é um sujeito experienciador, que é marcado com a posposição dativa mã, marcação não-canônica

\section{CONCLUSÃO}

Pode-se concluir, pelo que foi exposto neste artigo, que o modelo de desenvolvimento implementado para a Amazônia Brasileira não levou em consideração a peculiaridade do lugar. Em virtude disso, um potencial de riqueza ligado à biodiversidade que inclui fauna, flora, povos, línguas, só para citar alguns exemplos, foi e está colocado em risco. 
A riqueza produzida pela exploração dos recursos naturais não serviu para melhorar a qualidade de vida dos trabalhadores e muito menos dos povos que habitavam essas áreas. Pelo contrário, muitos trabalhadores depois do ciclo de exploração foram e são descartados e os donos da terra ficaram confinados em pequenas áreas, quando não foram obrigados a deixarem-nas.

No leque de perdas, uma das mais significativas, é a perda de muitas línguas indígenas, que ao serem extintas, levam consigo um repertório de conhecimento acumulado durante muitos anos de história dos povos que a falam. Além da perda de informações relacionadas à própria língua enquanto conhecimento linguístico.

Dentre os povos indígenas do Brasil, encontram-se os Mẽbêngôkre que ainda mantêm boa parte dos seus costumes ancestrais, variando o grau de manutenção de uma aldeia para outra. Este povo tem um dos maiores territórios e uma das maiores populações indígenas do Brasil e a língua ainda é falada como meio de comunicação do povo, mas ainda assim esta língua sofre com a pressão da língua envolvente, neste caso o português.

\section{REFERÊNCIAS}

BAGNO, Marcos. Preconceito linguístico: o que é, como se faz. São Paulo: Loyola, 2000.

CALDEIRA, Jorge. História da riqueza no Brasil. Rio de Janeiro: Estação Brasil, 2017.

CARELLI, Vincent. Martírio: um filme para indignar o Brasil. Documentário sobre o povo GuaraniKaiowá. Olinda (PE), 2016.

COUTO, Hildo Honório do. Linguística, ecologia e ecolinguística: contato de línguas. São Paulo: Contexto, 2009.

GALUCIO, Ana Vilacy M. et al. Documentação de línguas: novos caminhos da documentação de línguas dos povos originários. Disponível em: https://www.youtube.com/watch?v=iz_wmMHtVgc. Exibido em: 16 jun 2020.

JANSON, Tore. A história das línguas: uma introdução. São Paulo: Parábola, 2015.

LEA, Vanessa R. Riquezas intangíveis de pessoas partíveis: os Mẽbêngôkre (Kayapó) do Brasil Central. São Paulo: EDUSP, 2012.

MOORE, D. As línguas indígenas no Brasil hoje. In: MELLO, H.; ALTENHOFEN, C; RASO, T. (Org.). Os Contatos linguísticos no Brasil. 1ed. Belo Horizonte: Editora UFMG, 2011, p. 217-240. (solicito completar os dados do artigo ou é um capítulo de livro?) 
PAIVA, Vitor. Amazônia tem mais de 2,5 mil garimpos ilegais e contaminação por mercúrio vira regra. Disponível em: https://www.hypeness.com.br/2018/12/amazonia-tem-mais-de-25-milgarimpos-ilegais-e-contaminacao-por-mercurio-vira-regra/. Acesso em: 10 jan 2021.

PARDINI, Patrick. Amazônia indígena: a floresta como sujeito. Boletim do Museu Paraense Emílio Goeldi. Ciências Humanas, v. 15, n. 1, 2020.

PONTES, Nádia. O avanço ilegal da soja sobre a floresta. Disponível em: https://www.dw.com/ptbr/o-avan\%C3\%A7o-ilegal-da-soja-sobre-a-floresta/a-52242760. Acesso em: 10 jan 2021.

REDE XINGU+. Monitoramento Covid-19 na bacia do Xingu. Disponível em: https://www.xingumais.org.br/home. Acesso em: $30 \mathrm{dez} 2020$.

REVISTA EXAME. Disponível em: https://exame.com/brasil. Acesso em: 28 dez 2020.

LÓPEZ GARCÉS, Claudia; LAQUES, Anne-Elisabeth; COELHO-FERREIRA, Márlia. A beleza das roças: agrobiodiversidade Mebêngôkre-Kayapó em tempos de globalização. Boletim do Museu Paraense Emílio Goeldi. Ciências Humanas, Belém, v. 7, n. 2, 2012, p. 339-369.

RODRIGUES. Aryon Dall'Igna. Línguas indígenas: 500 anos de descobertas e perdas. D.E.L.T.A., v. 9, n.1, 1993, p. 83-103.

SOCIOAMBIENTAL. Terras indígenas do Brasil. Instituto Socioambiental. 2017. Disponível em: https://www.socioambiental.org/pt-br/mapas/terras-indigenas-do-brasil-janeiro-2017. Acesso em: 05 jan 2021.

SOCIOAMBIENTAL. Notícias. Instituto Socioambiental. Disponível em: https://www.socioambiental.org/pt-br/noticias-socioambientais. Acesso em: 17 jun 2020.

TODOROV, T. A Conquista da América: a questão do outro. In: PARDINI, Patrick 2020. Amazônia indígena: a floresta como sujeito. Boletim do Museu Paraense Emílio Goeldi. Ciências Humanas, 15(1), e20190009.

TURNER, Terence. Da cosmologia à história: resistência, adaptação e consciência social entre os Kayapó. Cadernos de Campo - n. 1, 1991. 